\title{
Respuesta gubernamental en tiempos de pandemia: contrastando México y Nueva Zelanda
}

\section{Government response to the Pandemic: contrasting Mexico and New Zealand. Miroslava Porta Lezama ${ }^{a}$, Jorge Castelán Meléndez ${ }^{b}$}

\begin{abstract}
:
In March 2020, at the beginning of the Sars-CoV-2 (COVID-19) pandemic, the disease caused alarm due to its spread and severity. Different countries reacted differently. Mexico's response was slow and erratic, and it eventually became highly politized. When comparing it with how New Zealand managed the situation, it becomes apparent that while Mexico pretended to mitigate the risk of contagion, New Zealand focused on suppressing the disease.

The effectiveness of the preventative non-pharmacological strategies promoted by the World Health Organization has been demonstrated in New Zealand, in stark contrast to the indifference displayed by governments like Mexico's, which continued to allow mass gatherings well into the pandemic. These diverging responses are reflected in the abysmal difference in the incidence and fatality rates between the two countries.

Beyond the gulf between Mexico and New Zealand in terms of the civic sensibility and responsibility displayed by their respective populations and political leaders, the pandemic has also laid bare the contrast in the percentage of Gross Domestic Product invested in Health, as a reflection of the overall economic differences. The pandemic and the resulting financial crisis have disproportionally affected low-income groups, which represent a bigger share of Mexico's total population.
\end{abstract}

\section{Keywords:}

COVID-19, management, pandemic, mitigation, suppressing, Mexico, New Zealand.

\section{Resumen:}

El inicio de la pandemia por Coronavirus 2019 en marzo de 2020 alarmó por su nivel de propagación y gravedad. Las acciones para contenerla han sido diferentes en función del país que se trate. México se caracterizó por su respuesta tardía y errática, eventualmente utilizada con fines políticos. Al compararla con el manejo de la pandemia en Nueva Zelanda que se enfocó en suprimirla, destaca la principal diferencia con México que pretendió tan sólo mitigarla.

Estrategias preventivas no farmacológicas promovidas por la Organización Mundial de la Salud han mostrado su efectividad en Nueva Zelanda, al contrario de la indiferencia de gobiernos como México que al inicio de la crisis sanitaria permitió la celebración de eventos masivos. Estas reacciones se han reflejado en la abismal diferencia en la incidencia y letalidad por COVID-19 entre ambos países. No debe perderse de vista que además de la sensibilidad y responsabilidad civil de cada país y de sus mandatarios, también influye el porcentaje del Producto Interno Bruto invertido en salud. También se han hecho evidentes las consecuencias que provocan las diferencias en el poder adquisitivo de la población en general: la pandemia no ha impactado de igual manera a los más desposeídos en comparación con quienes cuentan con más recursos de todo tipo.

\section{Palabras Clave:}

COVID-19, comparación manejo pandemia, México, Nueva Zelanda

\section{Introducción}

A finales del año 2019 se detectan los primeros casos de infección por Sars-CoV-2 (COVID-19) en el mundo, en marzo de 2020 la Organización Mundial de la Salud

Autor de Correspondencia, Universidad Autónoma del Estado de Hidalgo, https://orcid.org/0000-0002-0952-6207, Email: miroslava_porta8848@uaeh.edu.mx

b Universidad Autónoma del Estado de Hidalgo, https://orcid.org/0000-0001-6258-883X, Email: jcastelan@uaeh.edu.mx 
caracteriza a esta enfermedad como pandemia, que hasta el momento ha generado un gran impacto a escala mundial en los aspectos sanitario, económico, educativo y social, entre otros, las consecuencias de ello han sido de magnitud variable en los diferentes países, influido esto en parte por las diversas políticas implementadas por los gobiernos para enfrentar esta contingencia.

El objetivo de este trabajo es comparar algunas de las características de la respuesta gubernamental en dos países; México y Nueva Zelanda, que han influido hasta el momento en el comportamiento de la pandemia en estos países.

\section{Respuesta gubernamental en tiempos de pandemia: contrastando México y Nueva Zelanda}

El 11 de marzo de este año, el Director General de la Organización Mundial de la Salud (OMS), el Dr. Tedros Adhanom Ghebreyesus, anunció que la nueva enfermedad por el coronavirus 2019 (COVID-19) podía caracterizarse como una pandemia. Manifestó entonces su preocupación por los niveles alarmantes de propagación y gravedad, y los niveles alarmantes de inacción. Entonces había mundialmente 118,000 casos y 4291 muertes por esta causa. (1) Así fue como se inició la emergencia internacional de salud pública que ha costado al 8 de febrero de 2021 106,314,695 casos confirmados y $2,320,720$ muertes en todo el mundo. (2) Desde entonces, la OMS y la Organización Panamericana de la Salud (al igual que otros organismos) han agregado materiales de apoyo en sus páginas oficiales con contenidos técnicos que pueden asesorar a las personas sobre las medidas de protección de la salud y para prevenir la propagación del brote. $(3,4)$

En el caso de México, poco tiempo después de declarada la pandemia, se crea el 23 de marzo el Acuerdo donde el Consejo de Salubridad General reconoce la epidemia (sic) de enfermedad por el virus SARS-CoV2 (COVID-19) en México, como una enfermedad grave de atención prioritaria, y establecen las actividades de preparación y respuesta ante dicha epidemia (sic). En ese documento esencialmente se asigna la responsabilidad al Consejo de Salubridad General para que sancione las medidas de preparación, prevención y control de la epidemia (sic), (5) coordinadas por Secretaría de Salud, instituciones del Sistema Nacional de Salud, gobiernos estatales, organizaciones públicas y privadas, poderes legislativo y judicial, y la administración pública federal. La única novedad fue que todas estas instancias definirían planes de reconversión hospitalaria y expansión para garantizar la atención oportuna de los casos de la epidemia. Desde poco tiempo después ha sido evidente que ni es epidemia y ni se han atendido oportunamente los casos.

Las medidas más relevantes tomadas por parte de México, desde la Secretaría de Gobernación, y las instituciones involucradas fue la suspensión de actividades y de plazos administrativos, (6) algunas de ellas fueron Secretaría de Educación Pública, Suprema Corte de Justicia de la Nación, Auditoría Superior de la Federación, Procuraduría Federal del Consumidor, Secretaría de Comunicaciones y Transportes, Secretaría de Relaciones Exteriores, entre muchas otras.

Al día siguiente, el 24 de marzo se publica en el Diario Oficial de la Federación el Decreto por el que se establecen las medidas preventivas que se deberán implementar para la mitigación y control de los riesgos para la salud que implica la enfermedad por el virus SARSCoV2 (COVID-19). (7) En ese decreto se establece que la Secretaría de Salud informará al Presidente de la República sobre la situación existente cada 24 horas; también instruye a las dependencias y entidades de la administración pública federal a coordinarse y apoyar para instrumentar las medidas preventivas. Así de ambiguas es como iniciaron las acciones en México para atender la pandemia por COVID-19 y también es como han seguido 11 meses después donde la responsabilidad pasa de una figura a otra con casi nula presencia del Consejo de Salubridad General, del Sistema Nacional de Salud y del Secretario de Salud y sí desplazados por un Subsecretario a quien han convertido en necesario y protagónico, posea o no los méritos que lo justifiquen, desde luego, con y para el beneplácito del primer mandatario.

México tiene el 13vo lugar mundial en cuanto a casos confirmados, la tercera cifra más alta de muertes relacionadas al COVID-19 y una de las tasas de pruebas más bajas entre las principales economías, $(8,9)$ 37,612 pruebas por millón de habitantes. Se ha cursado por la pandemia sin aplicar pruebas masivas. Al principio se dictaron criterios de aplicación nacional y conforme avanzó el tiempo, la falta de estrategias y las contradicciones orillaron al gobierno federal a depositar la responsabilidad a cada entidad federativa.

En otras latitudes, en Nueva Zelanda, su reacción ha sido diferente desde el inicio de la pandemia. A principios de 2020, durante la pandemia de COVID-19, ese país implementó medidas nacionales de supresión de COVID19 destinadas a la eliminación de la enfermedad. Su enfoque fue suprimir y no mitigar la transmisión del nuevo coronavirus, sin una perspectiva de flexibilidad ante la presencia de muertes inevitables en aras de continuar con la economía activa.

A los 30 días de reconocida la emergencia sanitaria (todavía no pandemia), ellos establecieron los criterios para diagnosticar el COVID en hospitales y contaban con pruebas homologadas para detectar la enfermedad. 
Cuando el país contaba solo con 100 casos confirmados por coronavirus, el gobierno neozelandés tomó la decisión de detener la propagación, cerraron fronteras, además aplicaron una cuarentena por 14 días. (10)

Extendieron la cuarentena 10 días más, esta vez era un confinamiento mucho más estricto donde solo permanecían abiertas las tiendas de abarrotes, farmacias, hospitales y estaciones de servicio. Los viajes en vehículos particulares estaban restringidos. La primera ministra implementó una medida de 8,000 pruebas al día; hasta este día 8 de febrero de 2021 se han realizado $1,567,952$ pruebas, para una tasa de 313,459 por millón de habitantes, una de las tasas más altas del mundo.

Actualmente es indispensable identificar y aplicar intervenciones no farmacológicas contra el COVID-19. Lo que se ha demostrado como exitoso en países asiáticos ha sido el control de movilidad ciudadana, distanciamiento físico, prácticas de higiene con el lavado de manos como prioritario, detección y atención de casos, además de sus contactos. Para tal efecto ha sido preciso que el gobierno sea además de líder, ejemplo y con ello estimular la participación de la población.

Donde pareciera radicar la diferencia en el tratamiento de la pandemia es en el enfoque supresión vs. mitigación, es decir, detener la propagación vs. desacelerar la transmisión. El 8 de febrero mientras que en Nueva Zelanda se identificaron 2 casos nuevos y 2,324 casos acumulados desde el inicio de la pandemia, en México, en la misma fecha de identificaron 10,738 casos nuevos y 1'946,751 casos acumulados.

Desde luego que esto depende también de la población total y densidad demográfica, en México con 129'757,843 habitantes con una población relativa de 66 personas por $\mathrm{Km} 2$, por lo que podría ser esperable que haya más casos comparado con los 5,002,100 habitantes en Nueva Zelanda con 18 personas por $\mathrm{km}^{2}$. (11) Para poder dimensionar las diferencias entre ambos países podemos recurrir al número de casos de COVID-19 por millón de habitantes: en México es de 15,003 casos y en Nueva Zelanda es de 465 casos por millón de habitantes. También destaca que la tasa de letalidad es de $1.07 \%$ en Nueva Zelanda, mientras que en nuestro país es del $8.99 \%$.

Por otro lado, también debería contemplarse la riqueza, en México el Producto Interno Bruto (PIB) es de 20,703 dólares per cápita anual y en Nueva Zelanda es más del doble: 43,774 . El gasto en salud actual de ese país es de 9.17 por ciento del PIB $(1,12)$ y en nuestro territorio es de 2.5 por ciento. (13)

Para cubrir el paquete de servicios esenciales definido por la OMS y adaptado al caso mexicano se requieren 4.6 puntos del PIB, a lo que debe agregarse los gastos médicos que no fueron incluidos. Los servicios esenciales están clasificados en 4 categorías: (13)
1. Atención reproductiva, materna e infantil (planeación familiar, embarazo y parto, vacunación infantil, tratamiento infantil).

2. Enfermedades infecciosas (tuberculosis, VIH, malaria, agua y saneamiento).

3. Enfermedades crónicas no transmisibles (prevención de enfermedades cardiovasculares, control de diabetes, detección y tratamiento de cáncer, control de tabaco).

4. Capacidad y acceso a los servicios de salud (acceso a hospitales, densidad de trabajadores de la salud, acceso a medicinas esenciales, seguridad en salud).

Un aspecto relevante sobre el Sistema de Salud de México es su ambigüedad respecto a la cobertura debido a que depende del organismo que brinde la atención. Surgen las preguntas a quién cubre y qué servicios cubre, en especial en condiciones de pandemia. Se ha hecho manifiesto que se han visto rebasados en demanda, recursos humanos, materiales y capacitación.

Si algo se ha evidenciado es que, al igual que el soporte de la contingencia no es igual para toda la población, condicionado principalmente por la capacidad adquisitiva y de ahorro, el acceso a los servicios de salud también depende de los recursos económicos familiares disponibles. $Y$ para quienes no cuentan con ningún servicio de salud ya sea por falta seguridad institucional o por poca capacidad económica, esta es un indicio más de desigualdad con especial énfasis en los últimos meses en México y en el mundo.

En noviembre de 2020 Bloomberg.com (14) clasifica a través del análisis de diferentes parámetros entre ellos la tasa de casos, la tasa de mortalidad, la tasa de positividad de las pruebas, los acuerdos logrados para tener acceso a las vacunas, la capacidad del sistema de atención de salud local, el impacto de la restricciones relacionadas con el virus, entre otros, con ello establece un Ranking de Resiliencia de COVID, donde enlista en orden decreciente los mejores lugares para estar en la era del coronavirus, esto es, una instantánea de cómo se está reproduciendo la pandemia en este momento, al considerar también el acceso a la vacuna contra el coronavirus también nos da una idea de cómo estas economías se pueden desempeñar en el futuro, esta clasificación comprende a 53 lugares. En primer lugar, con la mayor puntuación (85.4) en este índice de resiliencia se encuentra Nueva Zelanda y en el lugar 53 con la menor puntuación (37.6) México. (15)

Esto no es definitivo, se puede ir modificando según cambien las circunstancias que le dan origen, pero es probable que la brecha entre las economías de la parte superior del ranking, con las que se encuentran en la parte inferior perdurará, con las consecuencias que ello implique.

En el momento de escribir este documento (febrero de 2021) en México se había iniciado ya la campaña de 
vacunación anti COVID-19, mientras que en Nueva Zelanda aún no empezaba. Nueva Zelanda ha eliminado con éxito la transmisión comunitaria de Covid-19, pero su frontera permanece cerrada a los extranjeros.

A manera de conclusión destaca que la perspectiva de supresión de la pandemia se contrapone con la de mitigación; son dos enfoques opuestos entre sí. Nueva Zelanda optó por detener la propagación; México prefirió desacelerar la transmisión.

Las recomendaciones de la OMS, tal vez de tan repetidas se han vuelto lugares comunes, sin embargo, con el ejemplo de Nueva Zelanda se hace evidente que el liderazgo gubernamental (que vaya más allá de su utilización con fines políticos), la detección de casos, el aislamiento, el rastreo de contactos, el distanciamiento social, las medidas de higiene y el compromiso de la población, son las estrategias no farmacológicas más apropiadas para contener emergencias sanitarias con las características del COVID-19.

El cierre de fronteras, implementar medidas estrictas de disminución de movilidad y de higiene, y vigilancia epidemiológica se reflejó en la disminución en velocidad e intensidad de la transmisión del COVID-19 en ese país. Por otro lado, no debe perderse de vista que Nueva Zelanda se trata de un territorio insular por lo que el control de sus fronteras es más fácil y la densidad poblacional también es completamente diferente.

Mientras que en Nueva Zelanda se establecieron pruebas y criterios diagnósticos y se preparó a los hospitales para atender esta nueva enfermedad, en México, con el mismo periodo de conocimiento de la situación de salud que se enfrentaría, se siguieron celebrando eventos masivos.

El número de casos por millón de habitantes es en México de 15,003, mientras que en nueva Zelanda es de 465. La tasa de letalidad es de $1 \%$ en Nueva Zelanda mientras que en nuestro país es cercana al $9 \%$. No debe perderse de vista que la riqueza de Nueva Zelanda es mayor que la de México (PIB de 43,774 vs 20,703 dólares per cápita anual, respectivamente), y que en el primero invierten el $9.17 \%$ de su PIB en salud, a diferencia de México que destina solamente el $2.5 \%$.

La economía de un país como Nueva Zelanda no puede compararse con la de México en el sentido de la capacidad financiera para soportar medidas del nivel que ha tomado aquel país. El impacto benéfico o no en el aspecto económico y sus consecuencias, será algo que podrá analizarse en los siguientes años, así como su efecto en función de su fortaleza presupuestal.

Planteando extremos, mientras que en un país se daba seguimiento a los contactos de sujetos positivos a COVID19, en otro, su primer mandatario estimulaba a la población a encomendarse a símbolos religiosos. La desigualdad originada por las carencias económicas acentúa las desventajas del más desposeído en aspectos de salud. Es muy probable que la brecha que se ha generado entre las diferentes economías como resultado de la pandemia se perpetúe en el largo plazo.

\section{Referencias}

[1] Organización Panamericana de la Salud. La OMS caracteriza a COVID19 como una pandemia - OPS/OMS | Organización Panamericana de la Salud. Disponible en: http://www.paho.org/es/noticias/11-3-2020oms-caracteriza-covid-19-como-pandemia (consultado 29/10/2020).

[2] Grupo Reforma. Especial COVID-19 en México. Covid-19 en México :: Grupo Reforma, Disponible en: https://gruporeforma.reforma.com/coronavirusmexico/ (consultado 09/02/2021).

[3] Organización Panamericana de la Salud. Enfermedad por el Coronavirus (COVID-19) | OPS/OMS | Organización Panamericana de la Salud. Disponible en: https://www.paho.org/es/tag/enfermedad-porcoronavirus-covid-19 (consultado 29/10/2020).

[4] World Health Organization. Nuevo coronavirus 2019, https://www.who.int/es/emergencies/diseases/novel-coronavirus-2019 (consultado 29/10/2020).

[5] Diario Oficial de la Federación. Acuerdo por el que el Consejo de Salubridad General reconoce la epidemia de enfermedad por el virus SARS-CoV2 (COVID-19) en México, como una enfermedad grave de atención prioritaria, así como se establecen las actividades de preparación y respuesta ante dicha epidemia.

[6] Diario Oficial de la Federación. Acuerdos derivados de la pandemia Covid-19 publicados en el Diario Oficial de la Federación. 27 de marzo de 2020 .

[7] Diario Oficial de la Federación. Decreto por el que se sanciona el Acuerdo por el que se establecen las medidas preventivas que se deberán implementar para la mitigación y control de los riesgos para la salud que implica la enfermedad por el virus SARS-CoV2 (COVID19). 24 de marzo de 2020.

[8] Coronavirus Update (Live): 107,389,998 Cases and 2,349,171 Deaths from COVID-19 Virus Pandemic - Worldometer (worldometers.info) Disponible en: https://www.worldometers.info/coronavirus/ (Consultado 09/02/2021).

[9] Staff F. México, bajo la lupa por manejo contra la pandemia de Covid19. Forbes México. Forbes México. Disponible en: https://www.forbes.com.mx/noticias-mexico-bajo-la-lupa-pormanejo-contra-la-pandemia-de-covid-19/ (2020, accessed 29 October 2020).

[10] Staff F. Estos son los pasos que siguió Nueva Zelanda para erradicar el coronavirus en 3 meses. Forbes Centroamérica.Información de negocios y estilo de vida para los líderes de Centroamérica y RD. Disponible en: https://forbescentroamerica.com/2020/06/09/estos-sonlos-pasos-que-siguio-nueva-zelanda-para-erradicar-el-coronavirus-en3-meses/ (consultado 29/10/2020).

[11] Statista. COVID-19 deaths per capita by country. Disponible en: https://www.statista.com/statistics/1104709/coronavirus-deathsworldwide-per-million-inhabitants/ (accessed 29 October 2020).

[12] World Bank. Current health expenditure (\% of GDP)|Data. Disponible en:

https://data.worldbank.org/indicator/SH.XPD.CHEX.GD.ZS?end=20 $17 \&$ start $=2000 \&$ view $=$ chart $($ Consultado 10/02/2021). 
Publicación semestral, Educación y Salud Boletín Científico Instituto de Ciencias de la Salud Universidad Autónoma del Estado de

Hidalgo, Vol. 10, No. 19 (2021) 65-69

[13] Centro de Investigación Económica y Presupuestaria, A.C. Sistemauniversal-de-salud.pdf. Disponible https://saludenmexico.ciep.mx/images/sistema-universal-de-salud.pdf (consultado 29/10/2020)

[14] New Zealand Approves First Covid-19 Vaccine, Awaits Delivery Bloomberg Disponible en: https://bloomberg.com/news/articles/2021 02-03/new-zealand-approves-first-covid-19-vaccine-awiats-delivery (consultado 11/02/2021)

[15] Chang R, Hong J, Varley K. El Ranking de Resiliencia COVID. Los mejores y peores lugares para estar en la era del coronavirus. Disponible en: https://www.bloomberg.com/graphics/covid-resilienceranking/ (consultado 29/11/2020). 